\title{
Effects of Different Tillage Methods on Bacterial Community and Enzyme Activity of Rhizosphere of Flue-Cured Tobacco in Yunnan Mountains
}

\author{
Wenjie Tong $^{1 \dagger}$, Min Yang ${ }^{2 \dagger}$, Hao Wang ${ }^{3}$, Xingbing Feng ${ }^{4}$, Liuchen Zhang ${ }^{4}$, Bin $\mathrm{Zhou}^{4}$, Feng Chen ${ }^{4}$, Feiyan Huang ${ }^{2}$, \\ Xiaolong Chen ${ }^{5}$, Yongzhan Cai ${ }^{6}$, Lei Yu ${ }^{2}$ and Xiaopeng Deng ${ }^{*}$ \\ ${ }^{1}$ Yunnan Academy of Tobacco Science, Kunming 650201, China \\ ${ }^{2}$ College of Agronomy, Yunnan Urban Agricultural Engineering \& Technological Research Center, Kunming University, \\ Kunming 650214, China \\ ${ }^{3}$ Chinese Tobacco Leaf Company, Beijing 100055, China \\ ${ }^{4}$ China National Tobacca Corporation Yunnan Company, Kunming 650011, China \\ ${ }^{5}$ Tobacco Leaf Purchase Center, China Tobacco Henan Industrial Co., Ltd., Zhengzhou 450000, China \\ ${ }^{6}$ Yunnan Provincial Tobacco Company Qujing Branch, Qujing 655000, China \\ *For correspondence: hddxp@163.com \\ ${ }^{\dagger}$ Contributed equally to this work and are co-first authors \\ Received 01 September 2020; Accepted 24 October 2020; Published 10 January 2021
}

\begin{abstract}
The microbial activity and soil enzyme activity are closely related to soil ecological functions. In this study, a flue-cured tobacco (Nicotiana tabacum) variety, K326, was planted and subjected to tillage methods of 20 cm of rotary tillage (control, RT20), $30 \mathrm{~cm}$ of deep tillage (DT30), $30 \mathrm{~cm}$ (ST30) and $40 \mathrm{~cm}$ (ST40) of subsoiling tillage. The expression profiling was conducted using Illumina MiSeq high-throughput sequencing, and the changes of bacterial community structure and enzyme activity in the rhizosphere soil under different tillage treatments were assessed. In the results, the DT30, ST30 and ST40 measures significantly reduced activity of catalase, increased the activities of urease, acid phosphatase and cellulose, and increased the diversity and richness of bacterial communities in the rhizosphere soil. Compared to RT20 (control), the Shannon index of DT30 treatment increased by 3.58\%, the Simpson index decreased by $47.46 \%$ and the ACE and Chao1 indexes of ST40 treatment increased by 2.77 and 3.38\%, respectively. At the phylum and genus levels, the dominant bacterial communities and relative abundance of the bacterial communities under different tillage treatments were significantly different. Compared with RT20, the DT30, ST30 and ST40 treatments increased the relative abundance of Gemmatimonadetes phylum by 30.93, 20.97 and $11.44 \%$ and the relative abundance of Nitrospirae phylum increased by $54.55,22.73$ and $11.36 \%$, respectively. In addition, the relative abundances of beneficial microorganisms such as Nocardioides, Gemmatimonas, and Sphingomonas genus in DT30 and ST30, ST40 treatments were more than control (RT20) treatments. In conclusion, the different ecological niche may create by great disturbance to soil in DT and ST treatments, the selection and adaptation of different microorganisms to the ecological niche may result in great changes in microbial species composition and community structure. (C) 2021 Friends Science Publishers
\end{abstract}

Keywords: Bacterial community; Deep tillage; Enzyme activity; Flue-cured tobacco; Mountainous; Subsoiling tillage

\section{Introduction}

Tillage is an indispensable and important part of agricultural production system. Different methods of tillage can affect soil structure (bulk density, porosity, aggregates, compactness) (Sun et al. 2018a), soil nutrients (nitrogen, phosphorus, potassium, organic matter) (Li et al. 2015) and micro-ecological environment (microbial biomass carbon, nitrogen, microbial quantity, diversity and soil enzyme activity) (Sun et al. 2018b; Fu et al. 2019).
Yunnan, an important tobacco leaf production area in China, its tobacco-growing soil is mainly mountainous along with red and yellow soil, with acidity, viscosity, barrenness, and drought to be the mainly characteristics. However, rotary and shallow tillage (REF) are the current tobacco farming methods. The long-term single tillage mode has resulted in soil compaction, thickening of the plow bottom and upward movement and shallow tillage. The year-round continuous cropping with heavy application of chemical fertilizers, and insufficient of organic fertilizers

To cite this paper: Tong W, M Yang, H Wang, X Feng, L Zhang, B Zhou, F Chen, F Huang, X Chen, Y Cai, L Yu, X Deng (2021). Effects of different tillage methods on bacterial community and enzyme activity of rhizosphere of flue-cured tobacco in Yunnan mountains. Intl J Agric Biol 25:345-353 
can eventually lead to the soil degradation, reduced soil microbial activity and high incidence of soil-borne diseases, which can seriously affect the growth, yield and quality of tobacco leaves, because the loose and deep soil are the fundamental for high-quality tobacco leaves production (She et al. 2017; Bai et al. 2019). Therefore, seeking farming measures that are conducive to improving soil quality and environment has theoretical and practical benefits for the above problems.

Reasonable farming measures can improve the structure and quality of the soil layer, coordinate the relationship among soil water, fertilizer, gas, heat and other factors, thereby effectively improving physical and chemical characteristics of the soil and micro-ecological environment (Sun et al. 2018a). Soil microbial activity is the core of the soil nutrient cycle (Wang et al. 2020), whereas soil enzyme activity and soil fertility directly reflect the dynamics of soil nutrient conversion (Tan et al. 2014). These are important indicators of quality of soil microecological environment (Pajares et al. 2011).

Different tillage methods at different depths may have great impact on soil enzyme activity, microbial community and distribution. Studies have shown that the nutrient content of no tillage (NT) field was high and the microbial community was unique (Smith et al. 2016). The soil with NT and crop residue retention had the highest diversity and abundance of bacterial community and NT carry positive impact for the growth of rhizobium fungi (Ceja-Navarro et al. 2010). Compared to the conventional plowing tillage (CT), NT treatment can effectively increase the activity of acid phosphatase, alkaline phosphatase and dehydrogenase (Heidari et al. 2016). However, in contrast to CT, reduced tillage and NT mulch, subsoiling mulch always has higher soil enzyme activity (Jin et al. 2009). In addition, clay, deep tillage and straw returning are more effective in increasing abundance of soil microbial community and activity of most enzymes ( $\mathrm{Ji}$ et al. 2014). Therefore, reasonable tillage methods should be selected according to crop species, planting areas and other local conditions.

Deep tillage (DT) uses plow and other agricultural tools to shovel, loosen and turn over the soil. Subsoiling tillage (ST) is a soil tillage measure that loosens the soil through loose parts such as subsoiling tillage shovel or chisel plow but without turning over the soil. A wealth of researches showed that DT and ST measures can effectively break the bottom of the soil plow and reduce the soil bulk density (Osunbitan et al. 2005). In contrary, the stubble crops and other plant residues into deeper soil layer are beneficial to increase the soil fertility, improve the soil permeability and promote root growth of crops (Lampurlanés and Cantero-Martínez 2003). In addition, DT and ST could improve physical properties of soil such as bulk density, porosity and moisture in tobacco field in mountainous areas, optimize the soil environment to some extent, promote the growth and development and optimize the spatial distribution and construction of root system (Liu et al. 2019).
However, the impacts of DT and ST measures on soil micro-ecological environment of tobacco field in Yunnan mountainous areas and its mechanism remain elusive. Therefore, this study aim to identify differences in composition and variations in bacterial communities in fluecured tobacco rhizosphere soil under different tillage treatments, identify the characteristics of enzyme activity and to analyze the effect mechanism of DT and ST measures on soil quality and efficiency improvement. The findings of this study are expected to provide reference for the application of DT and ST measures in tobacco field in Yunnan mountainous areas.

\section{Materials and Methods}

\section{Study area}

The experiment was conducted from March to September 2018 in Gaocang Street $\left(24^{\circ} 30^{\prime} \mathrm{N}, 103^{\circ} 32^{\prime} \mathrm{E}\right)$ of Hongta District, Yuxi City, a typical mountain tobacco growing area in Yunnan Dianzhong Tobacco area. The cultivated land is mainly gentle slope or terrace, the soil type is red soil, with previous crop of wheat. The test flue-cured tobacco variety is K326. The basic soil properties of the $0-20 \mathrm{~cm}$ soil layer before plowing are listed in Table 1.

\section{Experiment design and field management}

A single-factor randomized block arrangement was used with 4 treatments: rotary tillage $20 \mathrm{~cm}$ (RT20, control), using RT blade to cut, break up soil block, loose mixed layer soil, with rotary tillage depth $20 \mathrm{~cm}$; deep tillage 30 cm (DT30), through a tractor (Dongfanghong 904) 3 points mounted moldboard plow for deep plowing tillage, with deep tillage depth $30 \mathrm{~cm}$; subsoiling tillage $30 \mathrm{~cm}$ (ST30), subsoiling tillage $40 \mathrm{~cm}$ (ST40), through the tractor (Dongfanghong 904) 3 points mounted chisel subsoiler to loose soil without turning over soil layer. The height of subsoiling tillage machine and the depth of subsoiling tillage were controlled by tractor hydraulic pressure at 30 and 40 $\mathrm{cm}$, respectively.

After DT and ST, the tobacco fields were plough until the soil was deemed appropriate. Each treatment was repeated three times with routine single ridge transplanting. The row spacing was $1.2 \mathrm{~m}$ with plant spacing of $0.6 \mathrm{~m}$; the ridge height was $25 \mathrm{~cm}$ after transplanting. The pest control and other field management measures were carried out according to the local high-quality tobacco production management measures.

\section{Sample collection}

Tobacco plants are selected according to a five-point sampling method during the vigorous growth period. After removing the topsoil, entire tobacco plant was pulled up, the roots were carefully shaken to remove the loosely adhering 
soil, and the remaining attached soil was carefully collected by using sterile brushes and considered as the rhizosphere soil. The rhizosphere soil samples were thoroughly mixed and transported from the field to the laboratory in an icecooled container; in the laboratory, the samples were sieved ( $2 \mathrm{~mm}$ mesh) to remove plant debris and then split into two parts: one was air-dried for soil enzyme activity analysis, the second was stored in the refrigerator (MDF-U5386S, SANYO, JPN) at $-80^{\circ} \mathrm{C}$ for DNA extraction.

\section{Determination of soil enzyme activity}

The soil catalase activities, urease activities, acid phosphatase activities, invertase activities, protease activities and cellulase activities were determined as per instructions of Enzyme Activity Kit (Suzhou Keming Biotechnology Co., Ltd.). The activity of catalase was determined by measuring the solution absorbance at $240 \mathrm{~nm}$ after reaction with soil. Indophenol blue colorimetry was used to determine $\mathrm{NH}_{3}-\mathrm{N}$ produced by urease hydrolyzing urea. The activity of acid phosphatase was determined by measuring the content of phenol produced by hydrolysis of disodium diphenylphosphate catalyzed by acid phosphatase. Invertase activity was determined by measuring the content of reducing sugar produced by the degradation of sucrose by invertase. The protease activity was determined by measuring the tyrosine content produced by the soil acid protease catalyzing the hydrolysis of casein. The anthrone colorimetric method was used to determine the content of glucose produced by soil cellulase catalyzed cellulose degradation to determine cellulase activity.

\section{DNA extraction and PCR amplification}

The DNA extraction of each rhizosphere soil samples was performed as per instructions (FastDNA®SPIN Kit for Soil, MP, USA). The concentration and purity of DNA were determined by NanoDrop2000, and the quality of DNA extraction was detected by $1 \%$ agarose gel electrophoresis. Using two primers namely 338F (5'ACTCCTACGGGAGGCAGCAG-3') and 806R (5'GGACTACHVGGGTWTCTAAT -3'), PCR was performed to amplify the V3-V4 region of the $16 \mathrm{~S}$ rDNA, according to the following thermoprofile; $95^{\circ} \mathrm{C}$ predenaturation for $3 \mathrm{~min}, 27$ cycles (denatured at $95^{\circ} \mathrm{C}$ for $30 \mathrm{~s}$, annealed at $55^{\circ} \mathrm{C}$ for $30 \mathrm{~s}$, extended at $72^{\circ} \mathrm{C}$ for $45 \mathrm{~s}$ ), and finally extended at $72^{\circ} \mathrm{C}$ for $10 \mathrm{~min}$. Amplification mixture as set with following reagents; $20 \mu \mathrm{L}: 4 \mu \mathrm{L}$ 5*FastPfu buffer; $2 \mu \mathrm{L} 2.5 \mathrm{mmol} \cdot \mathrm{L}^{-1}$ dNTPs; $0.8 \mu \mathrm{L}$ Forward Primer $\left(5 \mu \mathrm{mol} \cdot \mathrm{L}^{-1}\right) ; 0.8 \mu \mathrm{L}$ Reverse Primer $(5$ $\left.\mu \mathrm{mol} \cdot \mathrm{L}^{-1}\right) ; 0.4 \mu \mathrm{L}$ FastPfu polymerase; $0.2 \mu \mathrm{L} \mathrm{BSA} ; 10 \mathrm{ng}$ DNA template; add $\mathrm{ddH}_{2} \mathrm{O}$ to $20 \mu \mathrm{L}$. The PCR products were recovered using $2 \%$ agarose gel, and further purified and recovered using the AxyPrep DNA Gel Extraction Kit (Axygen, U.S.A.) kit, and MiSeq sequencing by Shanghai Meiji Biomedical Technology Co., Ltd, China.

\section{Data quality control and analysis}

The original sequencing sequences were quality controlled using Trimmomatic software and FLASH (Caporaso et al. 2011) software was used for sequence assembly. The sequences were filtered by Usearch (Edgar 2013) software (v. 7.0) and the chimeric sequence was removed to obtain the effective sequence. The operational classification unit was divided by Uparse software (v. 7.1) at 97\% similarity level whereas the species annotation was performed by RDP classifier (Wang et al. 2007) software and SILVA (Altschul et al. 1990) database. The Mothur software (v. 1.30.1) was used to calculate the Coverage, Shannon, Simpson, ACE and Chao1 index, and evaluate the diversity and abundance index of the species; using the Bray-Curtis distance algorithm established by Qiime software (v. 1.7.0) to make Principal Coordinate Analysis (PCoA); using the Vegan software in R language to make RDA redundancy analysis to detect the relationship among environmental factors, samples, and bacterial communities or the relationship between two of them. The relationship among different environmental factors and the composition of microbial species were calculated by the Spearman correlation coefficient, and the correlation between microbial classification and environmental variables was evaluated by the correlation heatmap.

\section{Data processing}

Excel 2016 was used for data processing, S.P.S.S. 22.0 was used for statistical analysis, and Duncan's new multiple range test (MRT) was used for multiple comparison and analysis of data.

\section{Results}

\section{Changes of enzyme activity in rhizosphere soil under different tillage methods}

The activities of catalase, urease, acid phosphatase and cellulase under different tillage treatments were significantly different except that the changes in activities of sucrase and protease which remain less evident (Table 2). The activity of catalase was the highest in the rhizosphere soil of RT20 (control), and it was 47.83 and $68.16 \%$ lower respectively in DT30 and ST40 treatment, with significant difference (0.05) compared with RT20. The difference between DT30 and ST40 treatment was non-significant. It appeared, DT and ST were beneficial to increase the activity of urease, acid phosphatase and cellulase in the rhizosphere soil of fluecured tobacco. Compared to the RT20 (control), the activity of urease and cellulase in rhizosphere soil treated by DT30 increased by 24.41 and $19.17 \%$ respectively, and that of acid phosphatase in rhizosphere soil treated by ST30 and ST40 increased by 652.77 and $432.77 \%$ respectively. The difference was significant (0.05) among these treatments. 
Tong et al. / Intl J Agric Biol, Vol 25, No 2, 2021

Table 1: The basic soil properties of the $0-20 \mathrm{~cm}$ soil layer before plowing

\begin{tabular}{lllllllll}
\hline & $\mathrm{pH}$ & $\begin{array}{l}\text { Organic matter } \\
\left(\mathrm{g} \cdot \mathrm{kg}^{-1}\right)\end{array}$ & $\begin{array}{l}\text { Total N } \\
\left(\mathrm{g} \cdot \mathrm{kg}^{-1}\right)\end{array}$ & $\begin{array}{l}\text { Total P } \\
\left(\mathrm{g} \cdot \mathrm{kg}^{-1}\right)\end{array}$ & $\begin{array}{l}\text { Total K } \\
\left(\mathrm{g} \cdot \mathrm{kg}^{-1}\right)\end{array}$ & $\begin{array}{l}\text { Dissolved inorganic K } \\
\left(\mathrm{mg} \cdot \mathrm{kg}^{-1}\right)\end{array}$ & $\begin{array}{l}\text { Available P } \\
\left(\mathrm{mg} \cdot \mathrm{kg}^{-1}\right)\end{array}$ & $\begin{array}{l}\text { Available K } \\
\left(\mathrm{mg} \cdot \mathrm{kg}^{-1}\right)\end{array}$ \\
\hline Content / value & 6.72 & 17.80 & 0.75 & 1.28 & 7.70 & 79.10 & 37.40 & 204.00 \\
\hline
\end{tabular}

Table 2: Changes of soil enzyme activities in rhizosphere soil at different tillage treatments

\begin{tabular}{llllll}
\hline Treatments Catalase activities & $\begin{array}{l}\text { Urase activities } \\
\left(\mu \mathrm{mol} \cdot \mathrm{g} \cdot \mathrm{d}^{-1}\right)\end{array}$ & $\begin{array}{l}\text { Acid phosphatase activities } \\
\left(\mu \mathrm{mol} \cdot \mathrm{g} \cdot \mathrm{d}^{-1}\right)\end{array}$ & $\begin{array}{l}\text { Invertase activities } \\
\left(\mathrm{mg} \cdot \mathrm{g} \cdot \mathrm{d}^{-1}\right)\end{array}$ & $\begin{array}{l}\text { Protease activities } \\
\left(\mathrm{mg} \cdot \mathrm{g} \cdot \mathrm{d}^{-1}\right)\end{array}$ & $\begin{array}{l}\text { Cellulase activities } \\
\left(\mathrm{mg} \cdot \mathrm{g} \cdot \mathrm{d}^{-1}\right)\end{array}$ \\
\hline RT20 & $17.02 \pm 1.68 \mathrm{a}$ & $394.08 \pm 39.58 \mathrm{~b}$ & $2.35 \pm 0.13 \mathrm{c}$ & $37.84 \pm 1.79 \mathrm{a}$ & $3.34 \pm 0.23 \mathrm{a}$ \\
DT30 & $8.88 \pm 3.75 \mathrm{~b}$ & $490.29 \pm 27.86 \mathrm{a}$ & $3.58 \pm 0.88 \mathrm{c}$ & $30.88 \pm 1.62 \mathrm{~b}$ & $2.99 \pm 1.18 \mathrm{a}$ \\
ST30 & $16.80 \pm 1.85 \mathrm{a}$ & $400.20 \pm 18.99 \mathrm{~b}$ & $17.69 \pm 2.41 \mathrm{a}$ & $36.58 \pm 10.43 \mathrm{a}$ & $36.80 \pm 5.73 \mathrm{a}$ \\
ST40 & $5.42 \pm 0.30 \mathrm{~b}$ & $327.60 \pm 40.67 \mathrm{c}$ & $12.52 \pm 1.63 \mathrm{~b}$ & $39.06 \pm 6.84 \mathrm{a}$ & $2.95 \pm 1.55 \mathrm{a}$ \\
\hline
\end{tabular}

Note: Different small letters indicate significant difference among treatments at 0.05 level $(P<0.05)$, the same as below

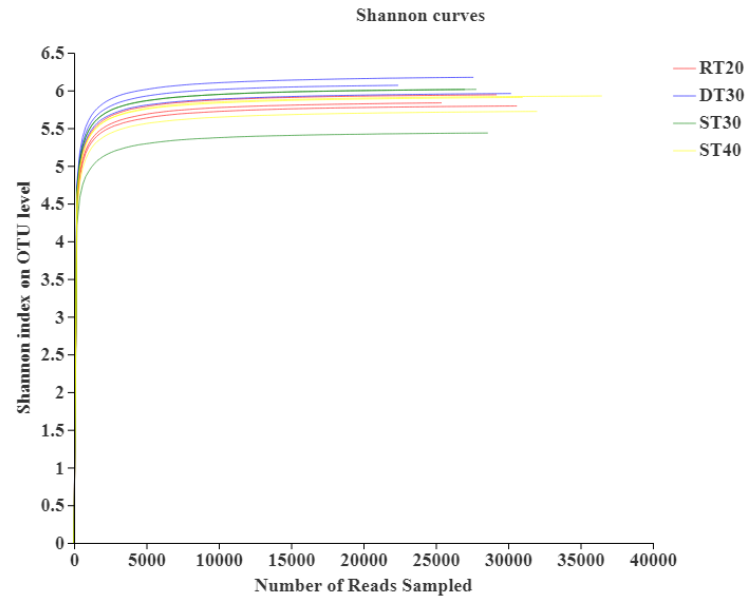

Fig. 1: Shannon index-based rarefaction curves on bacterial in rhizosphere soils at different tillage treatments

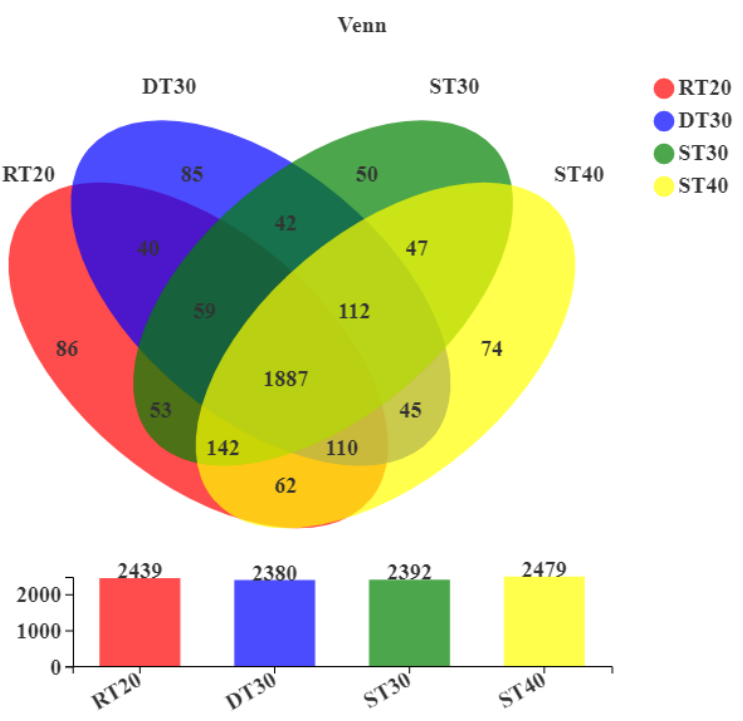

Fig. 2: Venn graph of bacterial OTUs distribution in rhizosphere soils at different tillage treatments

There was also significant difference in enzyme activity between DT and ST under the same tillage depth.
Compared to DT30, the soil, the activity of catalase and acid phosphatase in rhizosphere soil treated by ST30 increased by 89.19 and $394.13 \%$ respectively $(0.05)$, however, the activity of urease decreased by $18.37 \%(0.05)$. Under ST treatment, the impact of different soil depth on soil enzyme activity can vary. The activity of catalase, urease and acid phosphatase treated by ST40 was significantly lower than that of ST30, and decreased by $67.74,18.14$ and $29.23 \%(0.05)$. The activity of protease and cellulase also showed ST40 < ST30, but the difference was not significant. Together, the results showed that different tillage treatments and different tillage depth can significantly affect the enzyme activity of fluecured tobacco rhizosphere soil.

Variation characteristics of bacterial communities in rhizosphere soil under different tillage treatments

OTU richness and Alpha diversity of bacteria: The OTU richness and diversity index of the soil sample bacterial community at a similar level of $97 \%$ (Table 3). Fig. 1 showed that as the number of sequencing increases, the slope of the dilution curve gradually decreases and tends to flat. This indicates that the number of sequencing is sufficient. In this experiment, the coverage of the four treatments was greater than $98 \%$ (Table 3), highlighting that the sequencing read length was sufficient for this analysis.

The OTU richness of bacteria in the rhizosphere soil samples of different tillage treatments was ST40>RT20>ST30>DT30, however, the difference between four treatment was not significant. The distribution of bacterial OTUs by Venn diagram (Fig. 2) showed that there were a total of 9690 OTUs in four rhizosphere soils, and the same OTUs of the four treatments are 1887 , accounting for only $19.47 \%$ of the total number of OTUs; RT20 (control), DT30, ST30 and ST40 the number of OTUs peculiar to rhizosphere bacteria accounted for 3.53, 3.57, 2.09 and $2.99 \%$ of their respective total. Compared to the RT20 (control), number of peculiar OTUs treated with rhizosphere bacteria in ST30 and ST40 decreased by 41.86 and $13.95 \%$, respectively, indicating that there are significant differences in OTUs level of bacterial communities in the rhizosphere of tobacco plants under different tillage treatments. 
Rhizosphere Bacterial and Enzyme Activities of Tobacco / Intl J Agric Biol, Vol 25, No 2, 2021

Table 3: Bacterial OTU abundance and alpha diversity index in rhizosphere soils at different tillage treatments

\begin{tabular}{|c|c|c|c|c|c|c|c|c|}
\hline \multirow{2}{*}{ Treatments } & \multirow{2}{*}{ Raw number } & \multirow{2}{*}{ Effective number } & \multirow{2}{*}{ OTU abundance } & \multicolumn{4}{|c|}{ Alpha diversity } & \multirow{2}{*}{ Coverage $/ \%$} \\
\hline & & & & Shannon & Simpson & ACE & Chao1 & \\
\hline RT20 & 46739 & 26394 & 2439 & 5.86 & 0.0177 & 2266.10 & 2283.43 & $98.11 \%$ \\
\hline DT30 & 45083 & 24878 & 2380 & 6.07 & 0.0093 & 2259.36 & 2293.78 & $98.29 \%$ \\
\hline ST30 & 42843 & 26041 & 2392 & 5.82 & 0.0199 & 2215.41 & 2206.91 & $98.53 \%$ \\
\hline ST40 & 51677 & 30979 & 2479 & 5.85 & 0.0187 & 2328.87 & 2360.51 & $98.28 \%$ \\
\hline
\end{tabular}

Table 4: The relative abundances of bacterial Phylum (\%) in rhizosphere soils at different tillage treatments

\begin{tabular}{|c|c|c|c|c|}
\hline \multirow[t]{2}{*}{ Taxonomic category (Phylum) } & \multicolumn{4}{|c|}{$\%$ Bacterial abundance } \\
\hline & RT20 & DT30 & ST30 & ST40 \\
\hline Actinobacteria & $39.45 \pm 2.69 a$ & $37.31 \pm 5.81 \mathrm{a}$ & $42.57 \pm 6.66 \mathrm{a}$ & $39.32 \pm 4.74 a$ \\
\hline Proteobacteria & $29.24 \pm 1.68 \mathrm{a}$ & $26.22 \pm 2.11 \mathrm{a}$ & $30.35 \pm 7.92 \mathrm{a}$ & $31.29 \pm 7.98 \mathrm{a}$ \\
\hline Acidobacteria & $8.39 \pm 1.25 \mathrm{a}$ & $12.73 \pm 4.92 \mathrm{a}$ & $7.14 \pm 2.49 a$ & $8.35 \pm 3.04 \mathrm{a}$ \\
\hline Gemmatimonadetes & $4.72 \pm 0.40 b$ & $6.18 \pm 0.53 a$ & $5.71 \pm 1.13 \mathrm{ab}$ & $5.26 \pm 0.48 \mathrm{ab}$ \\
\hline Firmicutes & $1.69 \pm 0.15 a$ & $1.73 \pm 0.05 a$ & $1.96 \pm 0.65 \mathrm{a}$ & $1.53 \pm 0.58 \mathrm{a}$ \\
\hline Patescibacteria & $1.48 \pm 0.10 \mathrm{a}$ & $0.53 \pm 0.15 b$ & $0.95 \pm 0.54 \mathrm{ab}$ & $0.94 \pm 0.49 \mathrm{ab}$ \\
\hline Bacteroidetes & $0.98 \pm 0.32 \mathrm{a}$ & $0.75 \pm 0.10 \mathrm{a}$ & $0.77 \pm 0.35 a$ & $0.99 \pm 0.33 \mathrm{a}$ \\
\hline Cyanobacteria & $0.73 \pm 0.35 a$ & $0.71 \pm 0.39 \mathrm{a}$ & $0.72 \pm 0.32 \mathrm{a}$ & $0.51 \pm 0.24 \mathrm{a}$ \\
\hline others & $1.41 \pm 0.34 \mathrm{a}$ & $1.87 \pm 0.68 \mathrm{a}$ & $1.07 \pm 0.39 \mathrm{a}$ & $1.32 \pm 0.52 \mathrm{a}$ \\
\hline
\end{tabular}

Note: Different small letters indicate significant difference among treatments at 0.05 level $(P<0.05)$, the same as below

In addition, the diversity and richness of bacterial communities with different tillage treatments showed obvious differences. The diversity and richness index of ST30 treatment were lower than that of RT20 (control). However, the Shannon index of DT30 treatment increased by $3.58 \%$, whereas Simpson index decreased by $47.46 \%$ compared to RT20 (control). The species richness ACE and Chaol index of ST40 treatment increased by 2.77 and $3.38 \%$ compared to RT20 (control).

Bacterial community species composition and relative abundance: According to the results of species annotations of representative sequences in each OTU, the top 10 species with the highest abundance of bacteria in the phylum classification level in each rhizosphere soil sample were selected, and the species abundance of each sample gate level was counted (Table 4). The analysis showed that the bacterial flora of rhizosphere soil of tobacco plants under different tillage treatments is similar at the phylum level, mainly composed of Actinobacteria, Proteobacteria, Chloroflexi, Acidobacteria and Gemmatimonadetes. These five bacterial communities accounted for more than $90 \%$ of the total treatment, but the relative abundance of bacterial communities in different treatments were different.

Among them, the relative abundance of Gemmatimonadetes and Nitrospirae were higher than that of the control (RT20) in deep tillage (DT30) and subsoiling tillage (ST30, ST40) treatments. Compared to the RT20, the relative abundance of Gemmatimonadetes in DT30, ST30 and ST40 increased by 30.93, 20.97 and 11.44\%, respectively, and the relative abundance of Nitrospirae increased by $54.55,22.73$ and $11.36 \%$. The difference between DT30 and RT20 reached a significant level (0.05), however, the relative abundance of Patescibacteria in the deep tillage (DT30) and subsoiling tillage (ST30, ST40) treatments was lower than that of the control (RT20). The relative abundance of the Patescibacteria phylum of the three treatments was reduced by $64.19,35.81$ and $36.49 \%$, respectively compared with the control (RT20). The difference between DT30 and the control reached a significant level (0.05), however, for deep tillage (DT30) and subsoiling tillage (ST30, ST40) there was no significant difference in bacterial community composition at the gate level between treatments.

From the perspective of the classification level of the genus (Fig. 3), there are also obvious differences in the genus of rhizosphere soil bacterial flora under different tillage treatments, and the Sphingomonas treated by subsoiling tillage (ST30, ST40) is more than the control (RT20) increased by 10.95 and $2.16 \%$, respectively. The relative abundances of Gemmatimonas and Nocardioides treated by deep tillage (DT30) and subsoiling tillage (ST30, ST40) were higher than those of the control. The relative abundance of the three treatments of Gemmatimonas increased by 9.94 , 16.96 and $13.45 \%$ respectively compared with the control (RT20), and the relative abundance of Nocardioides increased by $42.57,66.34$ and $53.47 \%$. However, the relative abundances of Streptomyces and Bradyrhizobium treated by deep tillage (DT30) and subsoiling tillage (ST30, ST40) were at different degrees of reduction compared with the control (RT20). The relative abundance of three treatments of Streptomyces decreased by $9.27,7.58$ and $8.99 \%$ compared to the control (RT20), and the relative abundance of Bradyrhizobium decreased by 22.77, 4.02 and $13.39 \%$, respectively. In addition, the relative abundance of Sphingomonas, Bradyrhizobium, Gemmatimonas, Nocardioides, Terrabacter, Chujaibacter, and sphingobium showed subsoiling tillage (ST30, ST40) > deep tillage (DT30). PCoA cluster analysis of bacterial community composition: The PCoA was performed by Bray-Curtis distance algorithm (Fig. 4). The degree of interpretation of 


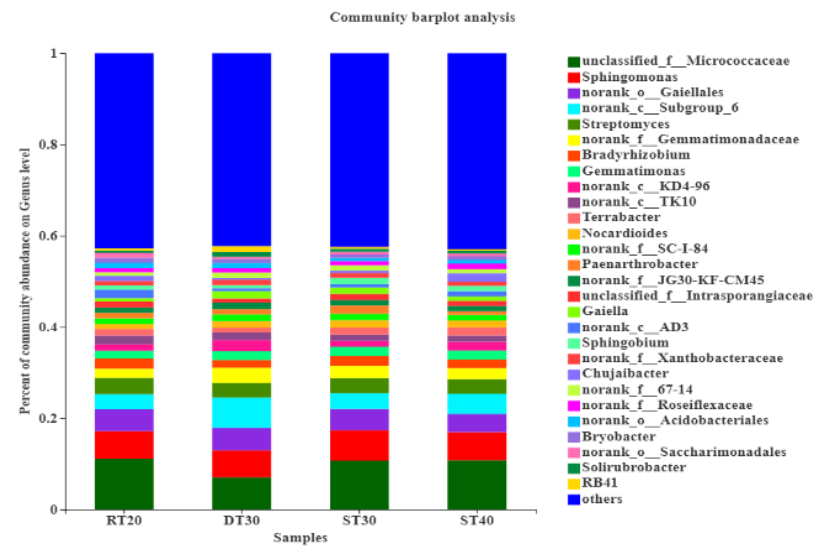

Fig. 3: The relative abundance of bacterial on genus level in rhizosphere soils at different tillage treatments

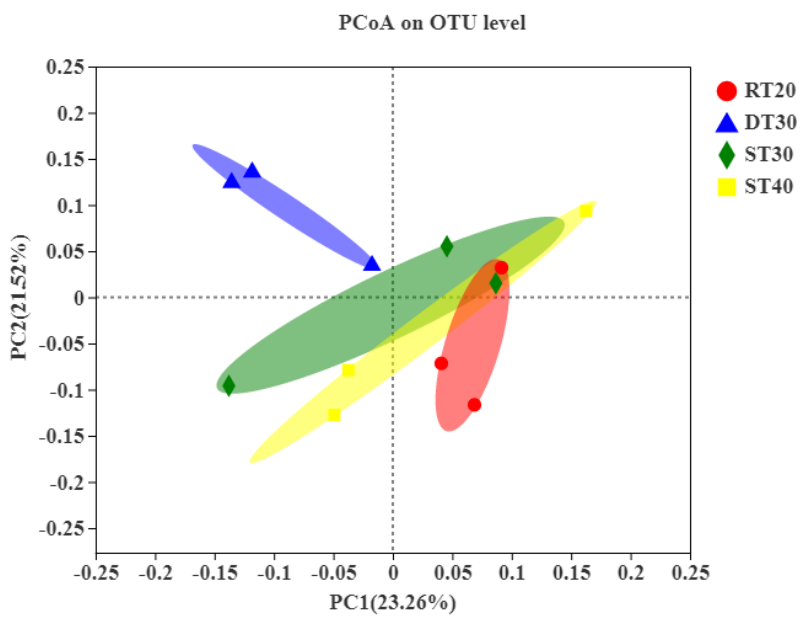

Fig. 4: PCoA cluster analysis of bacteria community in rhizosphere soils at different tillage treatments

principal component 1 (PC1) and principal component 2 (PC2) on sample differences were 23.26 and $21.52 \%$, respectively. The total account for the $44.78 \%$ of all soil samples. As shown in Fig. 4, both bacterial communities of rhizosphere soil treated by deep tillage (DT30) were distributed in the $2^{\text {nd }}$ quadrant, and the bacterial communities of rhizosphere soil treated by subsoiling tillage (ST30, ST40) were mainly distributed in the $1^{\text {st }}$ and $3^{\text {rd }}$ quadrant, while that of control (RT20) are mainly distributed in the $1^{\text {st }}$ and $4^{\text {th }}$ quadrants. It is obvious that the species composition of rhizosphere soil bacterial community under different tillage methods was significantly different. In addition, the bacterial communities treated by DT30 was the furthest from the control (RT20), followed by ST40 and ST30, which indicated that the larger disturbance to the soil during tillage would have a greater effect on the composition of the soil bacterial community. The relatively closer distance between ST30 and ST40 treatments indicated that the composition of rhizosphere soil of two bacterial communities treated by subsoiling tillage was highly similar.

Correlation analysis of bacterial community and environmental factors in rhizosphere soil under different tillage treatments

Redundancy analysis (RDA) is the PCA of environment factor constraint, which can reflect the sample and environment factor on the same 2-D sequence graph, and directly reflecting the relationship among the sample environment factor, the sample, the bacterial community, or the relationship between two of them. The degree of interpretation of two axes of RDA 1 and RDA 2 was 42.93 and $16.38 \%$, respectively. The cumulative degree of interpretation of the two axes was $59.31 \%$ (Fig. 5). It indicated that the correlation may vary at different soil enzyme activities (Fig. 5). There was positive correlation between the activity of urease (UA), cellulase (XA) and sucrase (SA), whereas a negative correlation between the activity of urease (UA), protease (PA), acid phosphatase (APA) and catalase (CA) was observed. There was a negative correlation between the activity of cellulase (XA), sucrase (SA) and catalase (CA) whereas there was positive correlation between the activity of protease (PA), acid phosphatase (APA) and catalase (CA). In addition, the change in soil enzyme activity had a certain impact on the distribution of bacterial community, of which urease (UA) and cellulase (XA) have the greatest impact, followed by protease (PA), catalase (CA) was the least.

The relationship between different environmental factors (soil enzyme activity) and microbial community was further calculated by using Spearman correlation coefficient. The correlation heat map between environmental factors and bacterial community composition showed that among the top 50 species for relative abundance at genus level, Nitrospira was significantly and positively correlated with sucrase activity (SA) (Fig. 6) with a correlation coefficient of 0.678 . The Marmoricola, Nocardioides and Sphingobium were significantly and positively correlated with acid phosphatase activity (APA) with a correlation coefficient of $0.601,0.580$ and 0.587, respectively. Bradyrhizobium, Pseudolabrys, Ellin6067, Reyranella, Streptomyces, Mesorhizobium, Mycobacterium were significantly and positively correlated with urease activity (UA) and the correlation coefficient was noticed to be $-0.587,-0.629,-0.622,-0.685,-0.741,-0.909$, 0.609 , respectively. In addition, other bacterial communities which have not been accurately classified and named such as norank_o_Elsterales, norank_f_Gemmatimonadaceae, unclassified_f Micrococcaceae, unclassified_f_Burkholderiaceae, have different correlations with different soil enzyme activities. Taken together, the results showed that there was a significant correlation between soil enzyme activity and bacterial community distribution in the rhizosphere of fluecured tobacco under different tillage treatments. 


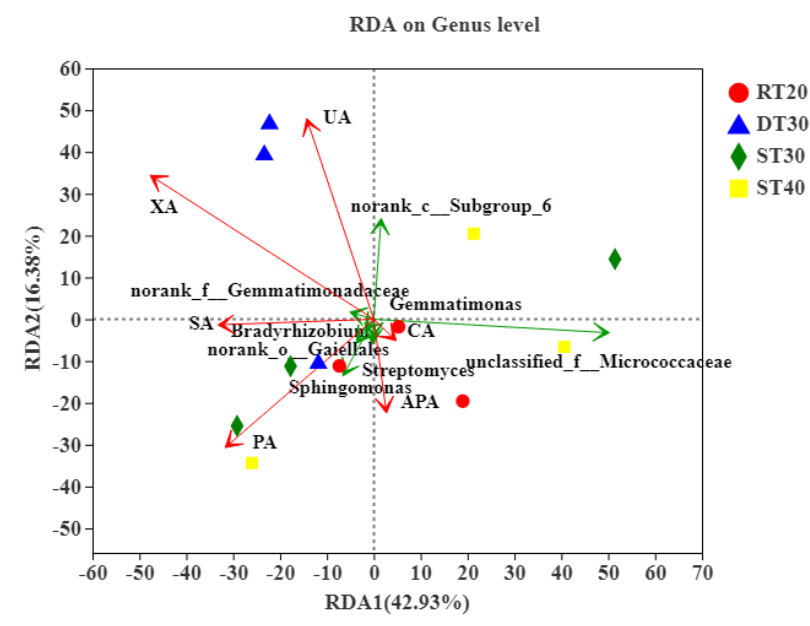

Fig. 5: Redundancy analysis of bacterial composition and environmental factors (soil enzyme activity) in rhizosphere soil at different tillage treatments

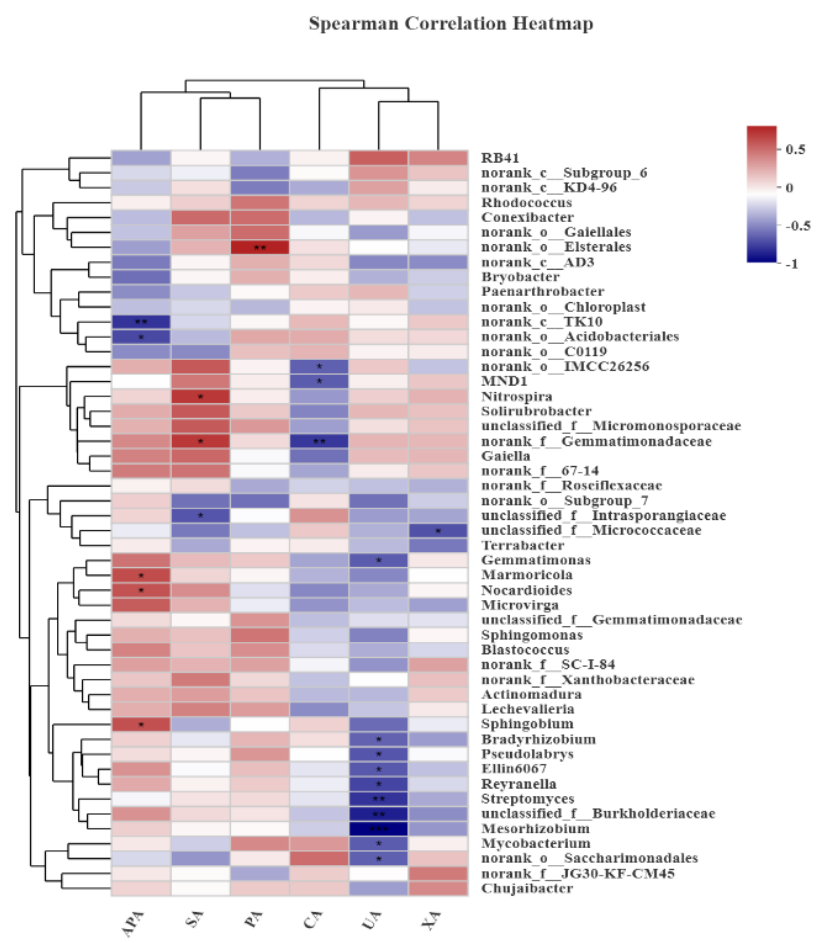

Fig. 6: Correlation analysis of different soil environmental factors and bacterial community composition on Genus level

\section{Discussion}

Many researches showed that soil tillage can cause great disturbance to soil, cause changes in soil structure, affect soil water conservation, ventilation and heat conduction, and change the vertical distribution of soil organic matter and soil nutrients in the surface layer of soil. Furthermore, it may have a certain impact on soil enzyme activity and microbial biomass (Curci et al. 1997; Munkholm et al. 2013).
Soil enzyme is an important component of the soil ecosystem, which is directly related to the dynamic transformation of soil nutrients and soil fertility (Benítez et al. 2000), wherein urease and phosphatase are the main hydrolases in soil. Urease can directly transform nitrogencontaining organic compounds in soil, promote the hydrolysis of amide peptide bond of nitrogen-containing organic compounds in soil, and reflect the level of nitrogen supply in soil to some extent. Phosphatase can promote the conversion of organic and inorganic phosphorus in soil and play an important role in the accumulation of available phosphorus in the soil. Cellulase and sucrase are mainly related to transformation of carbohydrate in soil and are positively correlated with soil fertility and the content of organic matter. Protease can catalyze the hydrolysis of protein into amino acid and the transformation of nitrogen nutrition in soil, and provide nitrogen source for crop growth. The catalases can decompose peroxide which is toxic to organism, so as to mitigate the damage to plant organism caused by the accumulation of peroxides in soil. These facts highlight that the soil enzyme activity is an important index to evaluate soil micro-environment quality.

In this study, both tillage method and tillage depth had significant impact on the enzyme activity of flue-cured tobacco rhizosphere soil in mountain area tobacco field. Compared with conventional rotary tillage (RT20), DT and ST could improve the activity of urease, acid phosphatase and cellulase in flue-cured tobacco rhizosphere soil. The activity of urease and cellulase treated by DT30 were increased by 24.41 and $19.17 \%$, respectively. The activity of acid phosphatase treated by ST30 and ST40 was increased by 652.77 and $432.77 \%$, respectively. At the same tillage depth $(30 \mathrm{~cm})$, the activity of catalase and acid phosphatase treated by DT was significantly lower than that of ST, but the activity of urease was significantly higher than that of ST. The results show that DT could break the bottom of the soil plough and turn the stubble crops and other plant residues into deeper soil layer, which is beneficial to increase the content of organic matter and the soil fertility, while ST could reduce the soil bulk density, increase soil porosity, facilitate soil gas exchange (Javed et al. 2013), promote the activation of aerobic microorganisms and the decomposition of minerals. Therefore, it was more beneficial to the improvement of soil enzyme activity. However, the effect of tillage on soil enzyme activity was influenced by soil depth, and the activities of catalase, urease, acid phosphatase, protease and cellulase in soil at different tillage depth under the same tillage treatment (ST) showed ST40 <ST30. Kheyrodin et al. (2012) have also found that urease activity decreased significantly with the increase of soil depth. Deng also reported that phosphatase activity decreased with the increase in soil depth (Deng and Tabatabai 1997). They believed the decrease may be related to a drop in organic carbon content. In conclusion, in addition to directly changing the physical properties of soil and regulating the factors such as water, fertilizer, gas and heat, DT and ST can 
significantly affect the enzyme activity related to soil organic matter conversion and soil nutrient cycling, and have a great impact on the formation of soil fertility.

Soil microorganism is the most active organism in soil and is sensitive to the change of soil environment (Diosma et al. 2006). It can represent the change of soil quality and ecological function in a timely manner. The composition and distribution of soil microbial community are easily influenced by agricultural tillage measures (Mueller et al. 2015; Sun et al. 2016). The results showed that the soil bacterial community composition and variety of flue-cured tobacco in mountain area tobacco field were affected by DT and ST treatment. The OTU abundance of bacteria in fluecured tobacco rhizosphere soil treated by different tillage methods was ST40> RT20> ST30> DT30. The specific OTUs number of bacteria treated by different tillage methods was RT20>DT30>ST40>ST30. The decrease of OTU abundance and the decrease of specific OTUs number in soil treated by DT and ST may be due to different ecological niche created by different tillage methods. The selection and adaptation of different microorganisms to the ecological niche may result in great changes in microbial species composition and community structure (Degrune et al. 2017).

A further analysis of bacterial community composition in the rhizosphere soil of flue-cured tobacco showed that the dominant bacterial community and relative abundance under different tillage methods may significantly vary at the phylum and genus levels. The relative abundance of Gemmatimonadetes and Nitrospirae treated by DT30 and ST (ST30, ST40) was significantly higher than that by conventional rotary tillage, and a group of beneficial soil microorganisms, such as the relative abundance of Nocardioides related to plant growth and biological protection, the genus Gemmatimonas which guide the phosphorus metabolism, and the genus Sphingomonas which has the ability of degrading aromatic compounds, were found in samples treated by DT30 and ST (ST30, ST40)>RT (RT20). The bacterial community diversity analysis showed that the species diversity Shannon index treated by DT30, the species abundance ACE and Chao1 index treated by ST40 were increased by $3.58,2.77$ and $3.38 \%$ than those treated by RT20, respectively. This aligns with previous studies on the positive effects of DT on soil microbial abundance (Ji et al. 2014).

Microbial diversity in rhizosphere soil is closely related to plant health, and high microbial diversity and activity are beneficial to create healthy and stable rhizosphere micro-ecological environment and promote plant growth (Mendes et al. 2015; Jaiswal et al. 2017). The promotion of soil beneficial microorganism growth by DT and ST measures in this study, and the improvement of soil microbial diversity, show that DT and ST have positive impact on improving the micro-ecological environment of flue-cured tobacco in mountain area tobacco field. However, it has caused great disturbance to soil in tillage, and destroyed the microbial community structure under traditional rotary tillage and shallow tillage, and the soil microbial growth and community structure reconstruction need a certain time. Therefore, the impact of long-term DT and ST treatments on bacterial community composition and diversity of flue-cured tobacco rhizosphere soil in mountain area tobacco fields warrant future research.

The microbial activity and soil enzyme activity are the strongest physiological activities in the microecological environment of rhizosphere soil. Correlation analysis shows that the bacterial community composition of flue-cured tobacco rhizosphere soil under different tillage treatments has a significant correlation with soil enzyme activity. Marmoricola, Nocardioides and Sphingobium were positively correlated with acid phosphatase activity (APA) whereas Bradyrhizobium, Streptomyces, Mesorhizobium, and Mycobacterium were all significantly negatively correlated with urease activity (UA). In addition, the phenomenon that the relative abundance of Nocardioides increased in the deep tillage and subsoiling tillage treatment is consistent with the phenomenon of the enhanced acid phosphatase activity in deep and subsoiling tillage treatment. At the same time, the decrease in the relative abundance of Bradyrhizobium and Streptomyces was also consistent with the significantly enhanced urease activity in the rhizosphere soil at deep and subsoiling tillage treatment. These results indicate that the biologically active factors in flue-cured tobacco rhizosphere soil together affect the micro-ecological environment in the rhizosphere of flue-cured tobacco. The positive effects of different tillage treatments on the soil of mountain tobacco fields are comprehensively reflected in many aspects.

\section{Conclusion}

Compared with the traditional rotary tillage mode in mountain tobacco fields, the soil structure under the traditional rotary tillage mode was broken during deep tillage and subsoiling, which had a great impact on the structure of soil plough layer. Deep tillage and subsoiling can not only improve soil permeability, but also create a micro ecological environment conducive to the growth of soil bacteria, promote the reconstruction of soil bacterial community structure, and play a positive role in improving the diversity and richness of soil bacteria. At the same time, deep tillage and subsoiling were conducive to the increase of relative abundance of beneficial bacteria (Nocardioides and Sphingomonas), and the improvement of soil enzyme activities (Urease, Acid Phosphatase and Cellulase). The stable and diversified bacterial community structure of rhizosphere soil was remolded under the joint action of tobacco plants and environment, and a healthy rhizosphere micro ecological environment was created. We concluded that the different ecological niche may create by great disturbance to soil in deep tillage and subsoiling tillage, the selection and adaptation of different microorganisms to the ecological niche may result in great changes in microbial species composition and community structure. 


\section{Author Contributions}

Xiaopeng Deng and Lei Yu conceived and designed the experiments; Wenjie Tong wrote the paper; Min Yang, Hao Wang, and Qingbing Feng performed the experiments; Liuchen Zhang, Bin Zhou and Feng Chen collected the data; Feiyan Huang analyzed the data; Xiaolong Chen and Yongzhan Cai contributed experimental materials.

\section{Acknowledgements}

This study was supported by the Project of Yunnan Branch Company of China Tobacco Corporation (No. 2018530000241016, 2019530000241011, 2018530000241020, 2020530000242010).

\section{References}

Altschul SF, W Gish, W Miller, EW Myers, DJ Lipman (1990). Basic local alignment search tool. J Mol Biol 215:403-410

Bai Y, G Wang, Y Cheng, P Shi, C Yang, H Yang, Z Xu (2019). Soil acidification in continuously cropped tobacco alters bacterial community structure and diversity via the accumulation of phenolic acid. Sci Rep 9; Article 12499

Benítez E, R Melgar, H Sainz, M Gómez, R Nogales (2000). Enzyme activities in the rhizosphere of pepper (Capsicum annuиm $\mathrm{L}$.) grown with olive cake mulches. Soil Biol Biochem 32:1829-1835

Caporaso JG, CL Lauber, WA Walters, D Berg-lyons, CA Lozupone, PJ Turnbaugh, N Fierer, R Knight (2011). Global patterns of 16S rRNA diversity at a depth of millions of sequences per sample. Proc Nat Acad Sci USA 108:4516-4522

Ceja-Navarro JA, FN Rivera-Orduña, L Patiño-Zúñiga, A Vila-Sanjurjo, J Crossa, B Govaerts, L Dendooven (2010). Phylogenetic and multivariate analyses to determine the effects of different tillage and residue management practices on soil bacterial communities. Appl Environ Microbiol 76:3685-3691

Curci M, MDR Pizzigallo, C Crecchio, R Mininni, P Ruggiero (1997). Effects of conventional tillage on biochemical properties of soils. Biol Fert Soils 25:1-6

Degrune F, N Theodorakopoulos, G Collinet, MP Hiel, B Bodson, B Taminlau, G Daube, M Vendenbol, M Hartmann T Nicolas, C Gilles, H Marie-Pierre, B Bernard, T Bernard, D Georges, V Micheline, H Martin (2017). Temporal dynamics of soil microbial communities below the seedbed under two contrasting tillage regimes. Front Microbiol 8; Article 1127

Deng SP, MA Tabatabai (1997). Effect of tillage and residue management on enzyme activities in soils: III. Phosphatases and arylsulfatase. Biol Fert Soils 24:141-146

Diosma G, M Aulicino, H Chidichimo, PA Balatti (2006). Effect of tillage and $\mathrm{N}$ fertilization on microbial physiological profile of soils cultivated with wheat. Soil Till Res 91:236-243

Edgar RC (2013). UPARSE: highly accurate OTU sequences from microbial amplicon reads. Nat Meth 10:996-998

Fu M, MM Hao, HY Hu, WC Ding, MZ Zhai, HY Zhang (2019). Responses of soil organic carbon and microbial community structure to different tillage patterns and straw returning for multiple years. $J$ Appl Ecol 30:3183-3194 (In Chinese with English abstract)

Heidari G, K Mohammadi, Y Sohrabi (2016). Responses of soil microbial biomass and enzyme activities to tillage and fertilization systems in soybean (Glycine $\max$ L.) production. Front Plant Sci 7; Article 1730

Jaiswal AK, Y Elad, I Paudel, ER Graber, E Cytryn, O Frenkel (2017). Linking the belowground microbial composition, diversity and activity to soilborne disease suppression and growth promotion of tomato amended with biochar. Sci Rep 7; Article 44382
Javed HMR, MSI Zamir, A Tanveer, M Yaseen (2013). Soil physical properties and spring maize yield as influenced by different tillage practices and integrated use of poultry manure with synthetic fertilizers. J Agric Res 51:277-287

Ji BY, H Hu, YL Zhao, XY Mu, K Liu, CH Li (2014). Effects of deep tillage and straw returning on soil microorganism and enzyme activities. Sci World J 2014; Article 451493

Jin K, S Sleutel, D Buchan, SD Neve, DX Cai, D Gabriels, JY Jin (2009). Changes of soil enzyme activities under different tillage practices in the Chinese Loess Plateau. Soil Till Res 104:115-120

Kheyrodin H, K Ghazvinian, M Taherian (2012). Tillage and manure effect on soil microbial biomass and respiration, and on enzyme activities. Afr J Biotechnol 11:14652-14659

Lampurlanés J, C Cantero-Martínez (2003). Soil bulk density and penetration resistance under different tillage and crop management systems and their relationship with barley root growth. Agron J 95:526-536

Li YJ, H Wang, JN Zhao, CH Huangfu, DL Yang (2015). Effects of tillage methods on soil physicochemical properties and biological characteristics in farmland: A review. $J$ Appl Ecol 26:939-948 (In Chinese with English abstract)

Liu Q, JJ Wang, XB Feng, LC Zhang, XP Deng, ED Ma, WJ Tong (2019). Effects of tillage methods on soil physical properties and spatial distribution of flue-cured tobacco (Nicotiana tabacum) roots in mountainous tobacco fields. Chin J Eco-Agric 27:1673-1681 (In Chinese with English abstract)

Mendes LW, SM Tsai, AA Navarrete, MD Hollander, JAV Veen, EE Kuramae (2015). Soil-Borne Microbiome: linking diversity to function. Microb Ecol 70:255-265

Mueller RC, J Belnap, CR Kuske (2015). Soil bacterial and fungal community responses to nitrogen addition across soil depth and microhabitat in an arid shrubland. Front Microbiol 6; Article 891

Munkholm LJ, RJ Heck, B Deen (2013). Long-term rotation and tillage effects on soil structure and crop yield. Soil Till Res 127:85-91

Osunbitan JA, DJ Oyedele, KO Adekalu (2005). Tillage effects on bulk density, hydraulic conductivity and strength of a loamy sand soil in southwestern Nigeria. Soil Till Res 82:57-64

Pajares S, JF Gallardo, G Masciandaro, B Ceccanti, JD Etchevers (2011). Enzyme activity as an indicator of soil quality changes in degraded cultivated Acrisols in the Mexican Trans-volcanic Belt. Land Degrad Dev 22:373-381

She SY, JJ Niu, C Zhang, YH Xiao, W Chen, LJ Dai, XD Liu, HQ Yin (2017). Significant relationship between soil bacterial community structure and incidence of bacterial wilt disease under continuous cropping system. Arch Microbiol 199:267-275

Smith CR, PL Blair, C Boyd, B Cody, A Hazel, A Hedrick, H Kathuria, P Khurana, B Kramer, K Muterspaw, C Peck, E Sells, J Skinner, C Tegeler, Z Wolfe (2016). Microbial community responses to soil tillage and crop rotation in a corn/soybean agroecosystem. Ecol Evol 6:8075-8084

Sun M, AX Ren, ZQ Gao, PR Wang, F Mo, LZ Xue, MM Lei (2018a) Long-term evaluation of tillage methods in fallow season for soil water storage, wheat yield and water use efficiency in semiarid southeast of the loess plateau. Field Crops Res 218:24-32

Sun R, W Li, W Dong, Y Tian, C Hu, B Liu (2018b). Tillage changes vertical distribution of soil bacterial and fungal communities. Front Microbiol 9; Article 699

Sun R, M Dsouza, JA Gilbert, XS Guo, DZ Wang, ZB Guo, YY Ni, HY Chu (2016). Fungal community composition in soils subjected to long-term chemical fertilization is most influenced by the type of organic matter. Environ Microbiol 18:5137-5150

Tan B, FZ Wu, WQ Yang, XH He (2014). Snow removal alters soil microbial biomass and enzyme activity in a Tibetan alpine forest. Appl Soil Ecol 76:34-41

Wang Q, GM Garrity, JM Tiedje, JR Cole (2007). Naive Bayesian classifier for rapid assignment of rRNA sequences into the new bacterial taxonomy. Appl Environ Microbiol 73:5261-5267

Wang YJ, L Liu, JF Yang, YM Duan, Y Luo, MJ Taherzadeh, YF Li, HK Li, MK Awasthi, ZY Zhao (2020). The diversity of microbial community and function varied in response to different Agric residues composting. Sci Total Environ 715; Article 136983 